\title{
Permeation of a Metalworking Fluid Through a Latex Glove Under Field Use Conditions
}

\author{
Wenhai Xu · Shane S. Que Hee
}

Received: 30 April 2009/Accepted: 9 September 2009/Published online: 26 September 2009

(C) The Author(s) 2009. This article is published with open access at Springerlink.com

\begin{abstract}
Whole glove testing for a metalworking fluid (MWF) in the field was performed for the first time. Green latex gloves used in a machine shop were exposed for $20 \mathrm{~min}$ to MWF. The permeated amount $\left(1.0 \pm 0.5 \mu \mathrm{g} / \mathrm{cm}^{2}\right)$ was higher than the threshold $\left(0.25 \mu \mathrm{g} / \mathrm{cm}^{2}\right)$ for the ASTM F739-99a closed-loop normalized breakthrough time.
\end{abstract}

Keywords Latex gloves - Metalworking fluids .

Whole glove permeation · Field study $\cdot$ Rinse method

The composition and the adverse health effects of metalworking fluids (MWFs) are well researched (Byers 1994; NIOSH 1998; Xu and Que Hee 2006a). MWFs are complex blended mixtures that not only contain petroleum distillate but also additives. The performance of disposable gloves against MWFs has been tested in the laboratory in permeation cells (Xu and Que Hee 2006b, 2007, 2008a). Only flat material can be examined (ASTM 2004), work factors are not simulated, the test temperature differs from the actual temperature of gloved hands, and whole gloves are not tested (Klingner and Boeniger 2002; ASTM 2004; Phalen and Que Hee 2008). In the present study, the first field study of glove permeation of a MWF, the permeation of whole gloves was investigated in a metalworking shop.

\section{W. Xu $\cdot$ S. S. Que Hee $(\bowtie)$}

Department of Environmental Health Sciences, UCLA Center for Occupational and Environmental Health, School of Public Health, University of California Los Angeles, 650 Charles Young Jr Drive South, Los Angeles, CA 90095-1772, USA e-mail: squehee@ucla.edu

Present Address:

$\mathrm{W} . \mathrm{Xu}$

Health Science Associates, 10771 Noel Street, Los Alamitos, CA 90720, USA

\section{Materials and Methods}

The metalworking fluid used was New Rapid Tap from Relton (Arcadia, CA). It contained mineral oil (CAS 64742-58-1, <50\% weight), chlorinated paraffins (CAS 61788-76-9, $<40 \%$ ), additives (patent, $<8 \%$ ), epoxidized soybean oil (CAS 8013-07-8, <1\%), olefin sulfide (patent, $<1 \%$ ), and cinnamon oil (trace). The glove was DermaThin, a green natural rubber latex glove (Best Manufacturing Company, Menlo, GA). Workers could have gloves as needed. The mass per unit area of three gloves was determined with cut pieces at the palm area. These data and the mass of the whole glove led to an average total outer surface area of $581 \pm 16 \mathrm{~cm}^{2}$. The glove thickness was $0.122 \pm 0.004 \mathrm{~mm}$, from seven measurements for each of three gloves. The worker operated a Hardinge Super-Precision lathe (Elmira, NY). Most manipulations required both hands. During the metalworking process, the worker held a tin can of Rapid Tap fluid upside down in his rightgloved hand to drip the MWF on the turning metal tube and lathe. MWF mist formed when MWF dripped on the turning tube. The worker then removed the tube from the lathe, and sprayed acetone to clean the tube. A cotton cloth was used to wipe the lathe, and treatment with compressed air and a sand cloth improved the finish. The whole cycle took some $60 \mathrm{~min}$. There was no local exhaust system. A machine guard was available but was flipped open to allow a better view. No respirators were used. The worker first washed his hands with liquid soap before putting on the method blank gloves. The latter were removed after $2 \mathrm{~min}$ without touching metal pieces or MWF. Fresh gloves were then donned, and two drops $(53 \pm 2 \mathrm{mg})$ of MWF was applied on the palm of the glove. The worker rubbed the palms of the two gloves together, but did not touch the glove on the backs of the hands. The worker did the shop 
job as indicated above. After $20 \mathrm{~min}$, the investigators, wearing fresh gloves, eased the exposed gloves off the worker's fingers by gentle pulling, and removed the gloves. The glove cuff was then tied by a rubber band. Throughout the process, care was taken to avoid contamination of the glove inner surface. Each exposed glove was deposited in a labeled acid-washed $50 \mathrm{~mL}$ wide mouth Pyrex Mason jar with Teflon lined screw cap. Transfer to the laboratory occurred within $10 \mathrm{~min}$. Three pairs of exposed gloves were obtained in total.

In the laboratory, the glove was taken out of the jar by gloved hands, and the rubber band removed. About $5 \mathrm{~mL}$ perfluorohexane ( $>98.5 \%$ purity) from Apollo Scientific, Bredbury, Cheshire, UK (Xu and Que Hee 2006a, 2008b; Phalen and Que Hee 2008) was pipetted into the inside of the glove through the small opening at the glove wrist-end. The opening was then closed, the glove shaken up and down for $10 \mathrm{~s}$, kneaded $15 \mathrm{~s}$ to ensure that perfluorohexane wet the entire inner surface, and shaken further for another $5 \mathrm{~s}$. The perfluorohexane was then dripped into a $20 \mathrm{~mL}$ acid-washed glass vial with Teflon-lined screw-cap. Five such rinses were done for each glove. Each rinse was analyzed by gas chromatography-mass spectrometry (GC-MS) by the total ion current monitoring mode $(\mathrm{m} / \mathrm{z}$ 50-400), and using the conditions described elsewhere (Xu and Que Hee 2006a) except for the GC column temperature program. The $30 \mathrm{~m} \times 0.25 \mathrm{~mm}$ HP-5 capillary column was held at $150^{\circ} \mathrm{C}$ for $15 \mathrm{~min}$, heated at $20^{\circ} \mathrm{C} / \mathrm{min}$ to $250^{\circ} \mathrm{C}$, and held at $250^{\circ} \mathrm{C}$ for $13 \mathrm{~min}$. Aliquots of $1.0 \mu \mathrm{L}$ of each rinse and the standard solutions of $0,22,44,66,88$, and $110 \mathrm{ng} / \mu \mathrm{L}$ of Rapid Tap MWF were injected in perfluorohexane solution. Standard curves were linearized by Box-Cox power transformation (Xu and Que Hee 2006a).

\section{Results and Discussion}

The glove fingers and palm area became black from manipulating the work piece and tools, especially on the thumb, index, and middle fingers. The lower quantifiable limit of MWF was $44 \mathrm{ng}$. The standard curve of GC-MS area versus injected MWF mass had a correlation coefficient $(r)$ of $0.912, p<0.01$, and a slope of $5.4 \times 10^{8}$ (area unit) $/ \mu \mathrm{g}$ and an intercept of $2.5 \times 10^{7}$ (area unit). A BoxCox power transformation indicated the optimum power was 0.1 . The new standard curve of area ${ }^{0.1}$ versus injected MWF mass, with a slope of 19 (area unit) ${ }^{0.1} / \mu \mathrm{g}$ and an intercept of 3.6 (area unit) ${ }^{0.1}$, had $r=0.982$, and $p<0.01$. The standard curve using transformed data fit all the MWF data. The method blank glove rinses showed no MWF. Thus the worker's hands were clean at the beginning of the test, and there was no contamination from handling by the investigators.

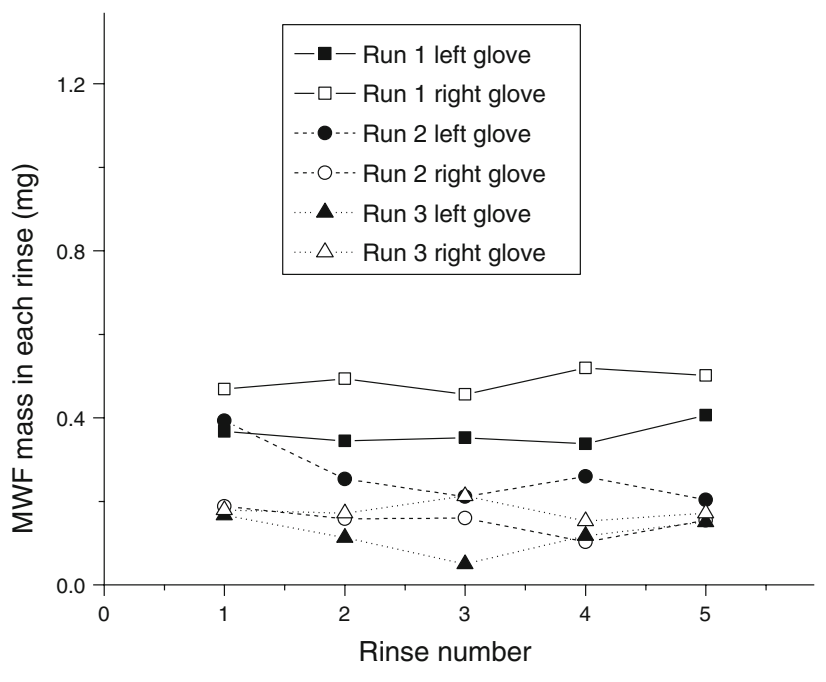

Fig. 1 The mass of MWF in each 5-mL rinse for each tested glove

The chromatogram for each rinse of the MWF exposed gloves exhibited a set of peaks from 17 to 24 min with highest response at $20.1 \mathrm{~min}$. The chromatograms for standards were similar. This confirmed utilization of the Rapid Tap MWF to generate standard curves with known concentrations in perfluorohexane to allow calculation of the MWF mass in each rinse (Fig. 1). The rinse masses did not decrease from the first rinse to the fifth rinse for the same glove as expected for a deposit on an inert, impermeable surface (except for Run 3 left glove for the first three rinses and Run 2 left glove for the first two rinses). The similar amounts of MWF in each rinse are probably extracted from the thin glove material interior. Therefore, the first rinse of the five was more representative of the MWF on the inner surface rather than summing the mass extracted in each set of five rinses. Assuming no losses to the worker's hand, the first rinse corresponded to 1.3, 1.6, $1.4,0.65,0.58$, and $0.62 \mu \mathrm{g} / \mathrm{cm}^{2}$ for the six gloves, respectively. The average amount was $1.0 \pm 0.5 \mu \mathrm{g} / \mathrm{cm}^{2}$ for all gloves, $1.1 \pm 0.4 \mu \mathrm{g} / \mathrm{cm}^{2}$ for left hand gloves, and $1.0 \pm 0.6 \mu \mathrm{g} / \mathrm{cm}^{2}$ for right hand gloves. The difference between the left and right hand gloves was not significant at $p \leq 0.05$. The above calculations used half the total outer surface area, since MWF exposed only the palm area. Since the solubility of the MWF in the glove material was at least ten times the highest concentration in these rinses, saturation conditions were not present. In the ASTM F73999a method closed loop system, the normalized breakthrough time threshold is defined at $0.25 \mu \mathrm{g} / \mathrm{cm}^{2}$ (ASTM 2004). In the present study, all glove samples exceeded the ASTM threshold, indicative of a problem.

Acknowledgments This project was funded by the UCLA Center for Occupational and Environmental Health (COEH), ASPH/NIOSH S1891-21/21, and NIOSH OH03754. Robert N. Phalen is thanked for 
valuable discussions. The UCLA Human Subjects Internal Review Board determined this study required no Human Subject Consent Form.

Open Access This article is distributed under the terms of the Creative Commons Attribution Noncommercial License which permits any noncommercial use, distribution, and reproduction in any medium, provided the original author(s) and source are credited.

\section{References}

ASTM (2004) Standard test method for resistance of protective clothing materials to permeation by liquids or gases under conditions of continuous contact. ASTM method F739-99a, annual book of ASTM standards, vol 11. West Conshohocken, PA, pp 1299-1309

Byers JP (1994) Metalworking Fluids. Marcel Dekker, New York

Klingner TD, Boeniger MF (2002) A critique of assumptions about selecting chemical-resistant gloves: a case for workplace evaluation of glove efficacy. Appl Occup Environ Hyg 17:360-367
NIOSH (1998) Criteria for a recommended standard: occupational exposure to metalworking fluids. DHHS (NIOSH) Public No 98102, Cincinnati, Ohio

Phalen RN, Que Hee SS (2008) A moving robotic hand system for whole glove permeation and penetration: captan and nitrile gloves. J Occup Environ Hyg 5:257-270

$\mathrm{Xu} \mathrm{W,} \mathrm{Que} \mathrm{Hee} \mathrm{SS} \mathrm{(2006a)} \mathrm{Gas} \mathrm{chromatography-mass} \mathrm{spectrometry}$ analysis of di-octyl disulfide in a straight oil metalworking fluid: application of differential permeation and Box-Cox transformation. J Chromatogr A 1101:25-31

Xu W, Que Hee SS (2006b) Permeation of a straight oil metalworking fluid through a disposable and a chemically protective nitrile glove. J Hazard Mater B137:709-715

Xu W, Que Hee SS (2007) Permeation of a straight oil metalworking fluid through disposable nitrile, chloroprene, vinyl, and latex gloves. J Hazard Mater B147:923-929

$\mathrm{Xu} \mathrm{W}$, Que Hee SS (2008a) Swelling of four glove materials challenged by six metalworking fluids. Arch Environ Contam Toxicol 54:1-8

$\mathrm{Xu} \mathrm{W,} \mathrm{Que} \mathrm{Hee} \mathrm{SS} \mathrm{(2008b)} \mathrm{Influence} \mathrm{of} \mathrm{collection} \mathrm{solvent} \mathrm{on}$ permeation of di-n-octyl disulfide through nitrile glove material. J Hazard Mater B151:692-698 